\title{
Faculty Development Framework: Experience of Kazakhstani Medical Schools
}

\author{
Guldana Akhmetova $^{1, *}$, Vaiva Hendrixson ${ }^{2,3}$, Ulmira Nuralieva ${ }^{4}$ \\ ${ }^{1}$ Department of History of Kazakhstan and Social Political Sciences, Medical University of Karaganda, Kazakhstan \\ ${ }^{2}$ Medical University of Karaganda, Kazakhstan \\ ${ }^{3}$ Faculty of Medicine of Vilnius University, Institute of Biomedical Sciences, Lithuania \\ ${ }^{4}$ Department of Medical Education Management, Ministry of Healthcare of the Republic of Kazakhstan, Kazakhstan
}

Received August 4, 2019; Revised September 11, 2019; Accepted September 20, 2019

Copyright $\subseteq 2019$ by authors, all rights reserved. Authors agree that this article remains permanently open access under the terms of the Creative Commons Attribution License 4.0 International License

\begin{abstract}
Kazakhstani higher education institutions have been facing the reformation of the education system since the country gained independence in 1991. The transition from the former Soviet education system to the Bologna process ${ }^{1}$ parameters required the reconciliation of a new education paradigm. This has changed faculty members' role from transmitting knowledge to facilitating the learning process. There are 124 higher education institutions in Kazakhstan, and six of them are medical schools. The latter lacked joint pedagogical competencies for faculty members in the medical field. With the support of the Ministry of Healthcare of the Republic of Kazakhstan and with the agreement of the leaders of the medical schools, a pilot project on faculty development was launched at Karaganda State Medical University in 2017. In June 2017, from September to November 2017, and from April to June 2018, over 416 faculty members were provided training courses on pedagogical skills. Instead of undergoing testing to assess of outcomes, faculty members responded to open-ended questions at the end of each course. In order to serve as a trainer at their home institutions, faculty members needed to score 85 or higher. According to the results, only 28 (11\%) of 250 in the 2017 cohort achieved the status of trainer, and 19 persons (11\%) of 166 in the 2018 cohort achieved the status of trainer. This article explores faculty perceptions of faculty development courses based on survey results, the challenges and opportunities of launching this project, and the experience of medical schools in Kazakhstan in shaping
\end{abstract}

1 The Bologna process is a series of ministerial meetings and agreements between European countries to ensure comparability in the standards and quality of higher-education qualifications. The process has created the European Higher Education Area under the Lisbon Recognition Convention. It is named after the University of Bologna, where the Bologna declaration was signed by education ministries from 29 European countries in 1999. a unique model for the framework of faculty development.

Keywords Faculty Development, Faculty Perception, Framework, Medical Schools, Kazakhstan

\section{Introduction}

The First President and the government of the Republic of Kazakhstan have been setting high political and economic goals for the development of the country. In order to move forward with great reforms, the country needs well-educated and highly qualified people, in other words solid human capital. This relies on the responsibility and preparedness of school teachers and faculty members at universities. Despite the 25 years of sovereignty of the country and the influx of a new generation that have been trained abroad by the President's Scholarship program, Bolashak [a Kazakh word meaning Future], the deeply rooted experiences of the former Soviet Union system still exist to a certain extent. In light of this, faculty training remains significant due to the necessities of responding to social and economic changes and the diversification of learners' backgrounds (Niehaus and Williams, 2016; Rigney, 2017; ten Cate and Simonia, 2018). Hence, faculty training courses require the modification and revision of training approaches in order to respond to changes.

In Kazakhstan there are various types of universities such as technical, military, humanities and medical schools. Medical schools have similar objectives compare to other schools. They are intertwined with a common medical frame. Indeed, working together in one area will enhance the possibility to generate new knowledge; for instance, Phuong et al. (2015), in their study regarding faculty development experiences in Southeast Asian countries, revealed the importance of sharing and bringing new 
knowledge to the region through faculty development experiences. New reforms therefore demand the cooperation and collaboration of professionals according to their field.

Due to the difficulty of altering a previously build system and in the process of change, the principles of the new education paradigm may conflict with the previous paradigm. Merging them requires an understanding of both of systems so that new paradigm can trigger changes; for instance, the experience of Asian countries in faculty development shows, that cultural aspects such as a hierarchical system inhibit directing an appropriate person to training and moreover neglect the English language proficiency requirement before sending candidates to training (Kim et al., 2017). This experience of avoiding the required selection criteria can also be found in Kazakhstani medical schools, because the hierarchical system still exists.

Another disadvantage to the previous system is a lack of trust in faculty training courses. This means faculty members need to provide paper-based confirmation about attendance at the training sessions. Indeed, photos taken from the training and the certificates that have been awarded prove that the money has been spent for the right purpose. However, in order to disseminate ideas related to the new education paradigm, it is important to understand the core idea of change rather than just awarding a certificate, as was mentioned in a study of Vietnamese universities that was based on the phenomenological approach (Phuong and McLean, 2016).

As a part of the new paradigm, the content of education and approaches to teaching and learning have been changing slightly. In Kazakhstan educational institutions follow the General Compulsory State Standards of Education (hereinafter referred to as the State Standards) that serve faculty members as guidance to lead their courses. Gradual changes in the State Standards provided academic freedom first to universities and later to faculty members in curriculum design. This has changed faculty members' previous competencies from delivering a course according to a prescribed curriculum to designing the curriculum for one's own course (Author, 2017, unpublished doctoral dissertation). However, the new generation of faculty members has been trained by professors whose knowledge and experience lie firmly in the Soviet era. Therefore, experienced faculty members who retained the mentality of the former Soviet period remain active players in the current reform.

Medical schools in Kazakhstan have meetings quarterly at the Respublikanskii Uchebno-Metodicheskii Sovet [Republican Academic Methodical Council] of Higher Medical Institutions of Kazakhstan. At this meeting, they discuss current challenges and in a cooperative way respond to issues that have emerged. Due to constant amendments in legal regulations, faculty competencies are a major topic. There is therefore a great responsibility to identify the main areas of faculty competencies. Leaders at each medical school have agreed to create one center where faculty members will be ensured training courses on pedagogical competencies. In other words, they will share their best experiences with each other and in that way facilitate a high quality of professional development. In February 2017, the Center for Transfer of Innovative Technologies (hereinafter referred to as Center) was established at Medical University of Karaganda (hereinafter referred to as MUK). MUK's best experiences in active methods of teaching and learning, research-based learning (RBL) and problem-based learning (PBL), distance learning, and simulation technologies of learning were incorporated into the professional development program. A constraint in the faculty development framework is that it was financed by the Ministry of Healthcare of the Republic of Kazakhstan (hereinafter referred to as the Ministry). This forced other higher medical schools and colleges to participate in the project rather than cooperate with MUK to create a unique model. In addition, a lack of confidence in further funding from the Ministry discouraged the sustainable existence of the Center.

This article examines faculty members' perceptions and experiences about professional development courses and the challenges and opportunities of the project launched at MUK. The structure of the article is the following. The first section describes MUK's faculty development framework, which is based on international experiences. The second section provides methods of research that helped to examine the issue. The third section presents findings and discussion based on survey results in the 2017 cohort and in the 2018 cohort concerning participants' perceptions about the courses. Finally, in the conclusion, there is an examination of the advantages and disadvantages of the project and of why only a few faculty members have passed the written exam even though the exam questions required only the respondents' own vision of the problem.

\section{MUK: Faculty Development Framework}

Prior to designing its own model, MUK analyzed international experiences in designing professional development frameworks. These include the professional development framework of Ireland (Brown, N., Bower, M., Skalicky, J.,Wood, L., Donovan, D., Loch,B., Bloom, W., and Joshi, N., 2010), the United Kingdom (The UK Professional Standards Framework, 2011), Australia (National Professional Development Framework, 2016), and the Best Evidenced Medical Education (Steinert et al., 2016). Although these international faculty development frameworks are organized in different ways, they nevertheless have similar ideas about the necessity of effective methods of teaching, designing and evaluating 
education programs; assessing the learning outcomes of students; meeting the needs of diverse students in class; using information technologies in the learning process; and delivering content in subjects and disciplines.

MUK selected pedagogical competencies that are based on research conducted by World Bank experts (Teacher Development and Management Overview of Policy Briefs, 2009) and the 2011 a State Standard on Continuing Learning of the Republic of Kazakhstan (hereinafter referred as the State Standard on CL) requirements (State Standard, 2011). Accordingly, the first pilot project launched with four courses (or modules): Effective Teaching; Researcher \& Research; Professional, Organizer \& Leader; and Problem-Based Learning. These courses (or modules) lasted 144 academic hours. The courses took place for four weeks, three of which were dedicated to distance learning on the platform Moodle and one week was allocated to face-to-face training sessions. This encouraged faculty members to continue their work and simultaneously enhance their qualification further, as has been pointed out in a study by Baran (2016).

During distance learning, faculty members were provided access on Moodle. The task of the distance component was a survey that faculty members were supposed to conduct at their home university. After submitting the distance component task, the faculty members had to take a written exam on which they needed to respond to eight questions related to the course (module) they attended. Faculty members that received a score of 85 and above were considered to have successfully completed the course (module) and were awarded the certificate of trainer. This means they could train their faculty members at their home institution. A total of $\mathbf{2 7 6}$ faculty members from medical schools were trained between September and December of 2017 and April and June of 2018.

Another module was provided for faculty members from clinical departments. Their courses included one week of face-to-face training of 36 academic hours out of 54 total hours. The content of the program included review lectures on active teaching methods. Due to the very short duration of the program, the faculty members trained by this course (module) were not required to be a trainer at their home institution. They had to take a written exam and respond to five questions related to the content of their course (module), however. Overall $\mathbf{1 4 0}$ faculty members from medical schools received training.

The MUK faculty development framework supports a circulating approach as has been suggested in the Ireland National Framework (National Professional Development Framework, 2016). This means there is no end of the process; it is continually renewing and innovating all the time according to current changes in the education system. For these new modules, previously trained trainers will be invited. Three months later all trainers will be asked to provide a report about how many people they have trained at their home institution and/or what challenges the trainers faced while nurturing the skills they have learned. Based on this and an additional monitoring survey, it is expected that the content of the program will be updated. Previous modules will be reorganized into open online courses and will serve as a hybrid MOOC tool for trainers to train their staff through a cascade method at home institutions (Perez-Sanagustin et al., 2017). This means that trainers who were trained at MUK and other faculty members can have access to these online modules and study the material.

\section{Methodology}

This is a qualitative study and research has employed mixed methods of research in exploring faculty members' experiences: a survey with open- and closed-ended questions, participant observations, and informal feedback of faculty members to ensure trustworthiness (Creswell, 2012).

Overall, 416 faculty members from medical schools took part in the survey. They all represented other Kazakhstani medical schools across the country. The timeframe of their training was diverse from June, 2017 till June, 2018. The duration of courses varied from one-week to four-week. The latter one divided in one-week face-to-face training and three-week online training. After completion of the course faculty members were required to provide written responses to eight/five questions according their courses. The major assessment criterion of the written exam was originality of a response. The exam was conducted online.

Daily observation of participants was used to see how faculty members were engaged and participated in the discussion, for example, what kind of questions they asked (Schutt, 2012). Very often they extrapolated their experiences in the discussion which triggered a vivid communication among participants from diverse medical schools. This method was also important to compare consistency of their performances with survey responses.

To explore to what extent the courses met the expectations of course participants (faculty members from medical schools), faculty members responded to a survey with closed- and open-ended questions. The survey consisted of five questions with four parts. The first part contained closed questions in which each participant had to evaluate from 1 to 5 (1=poor, 5=excellent) the course content, the learning environment, the diversity of active methods used to deliver the course, the engagement of the participants in the learning process, and the level of confidence of the participants to present and disseminate the newly obtained knowledge at their home institution. The remaining three parts were dedicated to open-ended questions. In the first part, participants needed to identify three skills that they gained through the learning process. In the second part, faculty members needed to identify three themes that were interesting and new for them. In the third part, they provided their recommendations and suggestions for further improvement. The open-ended questions were 
used to reveal faculty members' emic perspectives rather than imposing prescribed themes on them (Merriam and Tisdell, 2016). Participants were insured anonymity in order to reduce tension possibly caused by filling out the survey. All participants' responses were systematized and coded in an Excel file to draw a holistic picture of common perceptions. The responses were further coded under one concept. In the following section, analysis of the survey responses is provided.

Informal feedback was received in two ways, primarily, on the fifth day (after face-to-face trainings were completed), faculty members expressed their thoughts and impressions about training courses. These recommendations were discussed with the rest of the trainers that were involved in faculty training. Secondly, informal talks with participants that wished to share their impressions individually were also conducted.

\section{Findings}

\subsection{7- Survey Results}

This section explores the perception of faculty members concerning faculty development courses. First we present the results of a survey conducted in 2017 and then the analysis of one conducted in 2018. In addition, comparative analysis of faculty members' assessment outcomes is examined.

According to the survey results in 2017, most participants were satisfied (Diagram 1): $83 \%$ of respondents described the learning environment as comfortable; $73 \%$ of respondents considered the content of the courses as reliable for faculty development requirements; $92 \%$ of respondents confirmed that the program was designed clearly and well; $86 \%$ of respondents mentioned that trainers employed different active methods of teaching; $94 \%$ of respondents found the presentations accurate and clear; $94 \%$ felt that all participants were involved in the learning process; 93\% mentioned that they were asked for feedback; and $84 \%$ of respondents were ready to share at their home institutions the experiences they gained. However, 7 to $10 \%$ of respondents were unconfident about the prescribed statements. In other words, there were some participants whose expectations remained either unsatisfied or unmet.

The second part of the survey question was open-ended and it required respondents to identify three skills that were helpful for them (Table 1). The majority of respondents from the module entitled Professional, Organizer and Leader emphasized first, the design and evaluation of the education program, second, the 12 roles of a teacher (Harden, 1992), and third, the psychological aspects of community management. Other skills that were mentioned included providing feedback, demonstrating experiences in classes, working in small groups, developing scenarios, learning in outcome-based situations, planning, leadership skills, managing conflicts, mediating, developing oneself personally, communicating, and working as a member of a team. Participants engaged in discussions in small groups, watched video, played role games, and presented the results of their group work in class.

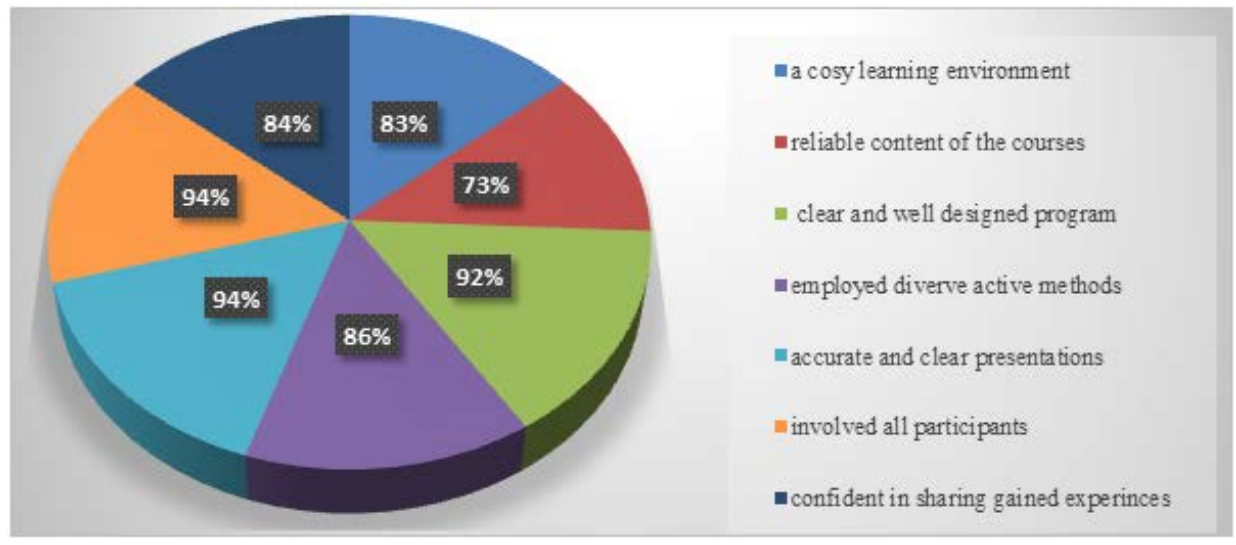

Diagram 1. Participants' Satisfaction by the Faculty Development Program

Table 1. Three main gained skills identified by Faculty Members

\begin{tabular}{|l|l|l|l|}
\hline \multicolumn{1}{|c|}{ Modules } & \multicolumn{3}{|c|}{ Gained Skills } \\
\hline $\begin{array}{l}\text { Professional, Organizer and } \\
\text { Leader }\end{array}$ & $\begin{array}{l}\text { designing and evaluation of the } \\
\text { education program }\end{array}$ & $\begin{array}{l}\text { grasping the 12 roles of a } \\
\text { teacher }\end{array}$ & $\begin{array}{l}\text { understanding a community } \\
\text { management concept }\end{array}$ \\
\hline Effective Teaching & Making Presentations & $\begin{array}{l}\text { grasping the 12 roles of a } \\
\text { teacher }\end{array}$ & $\begin{array}{l}\text { designing online courses on } \\
\text { Moodle }\end{array}$ \\
\hline Problem-based Learning & $\begin{array}{l}\text { understanding of problem-based } \\
\text { learning }\end{array}$ & $\begin{array}{l}\text { working with the Open } \\
\text { Labyrinth online platform }\end{array}$ & designing case studies \\
\hline $\begin{array}{l}\text { One-week course (on Active } \\
\text { Methods of Teaching) }\end{array}$ & $\begin{array}{l}\text { understanding of the main principles } \\
\text { involved in active methods of learning }\end{array}$ & preparing presentations & working in small groups \\
\hline
\end{tabular}


The opinion of respondents from the module entitled Effective Teaching aligned with the previous module in certain aspects. Faculty members gave first place to 10 Steps in a Presentation. It is worth mentioning that this theme was delivered by the rector, and all participants presented their own presentation after taking into account the tips provided for developing a good presentation. At the beginning, faculty members stated that they did not consider the topic new and that they were aware of the tips provided. However, while presenting their own work, they realized that they were repeating the same mistakes such as a lack of clarity in defining the learning objectives, the absence of a table of contents and a logical sequence of slides, the limited engagement of participants and an insufficient amount of time given to asking for their opinions, and lack of eye contact and asking whether listeners had questions or not. Discussion was moderated by the rector, but drawbacks were found and highlighted by the participants themselves. The second skill mentioned was the 12 roles of a teacher (Harden, 1992). This topic triggered discussion among participants in terms of how a faculty member who is busy teaching should fulfil all other necessary roles such as designing course curriculum, conducting research and getting published, and taking care of patients. The faculty members were divided in five groups, and they then discussed their roles at their home institutions. After a short break, the trainers provided a diagrammatic comparison of their responses. This helped them to visualize different perspectives and their priorities in their teaching position. The third skill that was pointed out was creating online courses on Moodle. Medical schools in Kazakhstan are still discussing which platform to use: Sirius, Moodle, or Platonus. Moodle is therefore a new platform for all of them. MUK is against imposing its own experience in the use of Moodle, but as part of the discussion they were trying to identify which platforms would be convenient for all to use. The question remains open for further discussion.

MUK, in the frame of an Erasmus+ CBHE project grant, has developed problem-based learning strategies. The version of the program that was developed has been tested at MUK. It took two years to align PBL to the curriculum of existing programs. In the frame of faculty training, MUK's experiences with problem-based learning have been shared with our colleagues from other medical schools. According to survey results, the participants in this module pointed out, the following: first, they gained an understanding of problem-based learning; second, they liked working with the Open Labyrinth online platform, where they tried in groups to create medical cases; and third, the process of creating cases itself empowered them. For this module, four special rooms were supplied with equipment and trained MUK staff members who were part of the project demonstrated their regular classes to visiting participants. This experience showed the participants how MUK has developed clinical cases. After this session, participants were required to develop their own clinical cases in groups.

The experience of faculty members from clinical departments trained mainly on active methods of teaching showed that first, they gained an understanding of the main principles involved in active methods of learning; second, they emphasized the importance of developing presentation skills; and finally, they experienced working in small groups and obtained advantages from that. Informal conversations with participants made us realize that the program content for a one-week course was very intensive. From the perspective of MUK, we would like to provide diverse methods of teaching so that faculty members can decide on their own which of the methods is most convenient for their classes. However, even though that faculty members realized which method was important for them, they lacked the conceptual understanding to employ them properly. Therefore, the team of MUK trainers suggested that faculty members should attend four-week courses where they could obtain a holistic understanding of the concept, for instance, of problem-based learning.

\subsection{8- Survey Results}

According to the results of the survey conducted in 2018, overall participants have remained satisfied with the faculty development courses. In terms of the closed-ended questions, almost $98 \%$ of respondents gave high scores to the statements related to comfortable learning environment, content of the program, engagement of participants in the learning process, and use of diverse teaching methods. However, a number of participants from one-week courses indicated they were not confident about sharing their experiences. Consequently, $27.5 \%$ of respondents indicated that they had doubts about their ability to be a trainer at their home institution.

The list of skills that faculty members gained throughout the learning process is diverse (Table 2). Faculty members from the one-week module identified the following: first, their work on Moodle, because faculty members did not have to listen to lectures but rather created their own courses, downloaded materials, and practiced in reality; second, methods of PBL and RBL where MUK trainers shared their experiences about how they implement these methods; the third is simulation learning, for which participants visited the Center for Practical Skills to practice clinical skills on medical mannequins; and finally, research in medical education, such as how to formulate research questions, project planning, and research design. 
Table 2. Obtained Skills that were emphasized by Faculty Members

\begin{tabular}{|c|c|c|c|c|}
\hline Modules & \multicolumn{4}{|c|}{ Gained Skills } \\
\hline $\begin{array}{c}\text { One-week course (on Active } \\
\text { Methods of Teaching) }\end{array}$ & to work on Moodle & $\begin{array}{l}\text { to apply PBL and RBL } \\
\text { methods }\end{array}$ & $\begin{array}{c}\text { to practice clinical skills } \\
\text { in simulation learning }\end{array}$ & \\
\hline Researcher and Research & research skills & $\begin{array}{l}\text { to prepare a good } \\
\text { presentation }\end{array}$ & to design a new project & $\begin{array}{l}\text { to identify the } \\
\text { Hirsh index }\end{array}$ \\
\hline $\begin{array}{c}\text { Professional, Organizer and } \\
\text { Leader }\end{array}$ & $\begin{array}{l}\text { to design and develop } \\
\text { education programs }\end{array}$ & styles of leaderships & to work in small groups & $\begin{array}{c}\text { roles of a } \\
\text { teacher }\end{array}$ \\
\hline Effective Teaching & $\begin{array}{l}\text { self-reflection and } \\
\text { self-assessment }\end{array}$ & $\begin{array}{l}\text { methods of assessment and } \\
\text { the pyramid of Miller }\end{array}$ & $\begin{array}{l}\text { to apply SMART } \\
\text { technology }\end{array}$ & $\begin{array}{l}\text { to compose test } \\
\text { questions }\end{array}$ \\
\hline
\end{tabular}

Participants in the module Researcher and Research indicated four major skills that they learned: these are first, research skills, regarding how to write an article, analyze data, and prepare an abstract; second, how to prepare a good presentation; third, how to design a new project; and fourth, to identify the Hirsh index. For the module Professional, Organizer and Leader participants highlighted, first, development of education programs (this theme is quite significant since the academic freedom to design course curriculum has been growing); second, styles of leaderships; third, work in small groups; and fourth, roles of a teacher (Harden, 1992). Participants in the module Effective Teaching found the following skills useful: first, self-reflection and self-assessment; second, methods of assessment and the pyramid of Miller; third, the application of SMART technology and design and assessment of learning objectives; and fourth, composing test questions and making a good presentation.

\subsection{Assessment Results}

The forms used to make a final determination of faculty members' knowledge have been discussed a lot. Regular testing has been convenient, because it requires less time to count correct responses. The computer automatically calculates and provides gained scores. However, computer testing caused debate among the experienced medical workers who delivered classes. For instance, according to the results of the testing by the Ministry in 2017, only 140 MUK faculty members out of 600 successfully confirmed their knowledge in the areas of teaching methodology and their main subject. Over 300 faculty members gained less than 30 points out of 50 questions on pedagogical competencies, even though most of them have a solid background in teaching. The implications of this testing were discussed with employees of the Ministry at the conference at MUK in October 2018. In order to draw a positive experience from this, MUK decided to provide a written exam for faculty members.

MUK trainers expected that a written exam would be much easier for faculty members. However, only 28 (11\%) from the 2017 cohort and 19 (11\%) from the 2018 cohort confirmed their knowledge and skills as a trainer. This means they gained scores of 85 and above for their written responses. One of the challenges for MUK trainers within the assessment of the written exam was plagiarism. There were cases when answers were copy-pasted from articles that could easily be found online. An attempt to resolve this issue complicated the situation. At the beginning of each course, we mentioned in the work plan and syllabi that plagiarism was unacceptable.

\section{Discussion}

This section describes the major challenges that lay in the implementation of the pilot.

The pilot project on faculty development was first launched in June 2017. The preparation stage started in February 2017, however. The first experience brought many unexpected challenges. One of the major obstacles was the stavka system. A legacy of the former Soviet time, in this system each faculty member was allocated a certain number of academic hours at their home institution, and they had to deliver those academic hours (Zuev and Lentyaeva, 2015). This inhibited face-to-face training requiring the physical presence of each participant. Consequently, younger and inexperienced members were delegated to attend the training courses. This had an impact on the quality of the staff members who were sent to faculty development courses. Another challenge was the business trip expenses of faculty members. Although expenses for the course were covered by the Ministry, the universities were supposed to cover the travel expenses of faculty members. This created unplanned expenditures for universities and as a consequence decreased the number of participants that a university could support. Last but not least, the attitude of faculty members towards the program proved to be a challenge. Although trainers reminded all participants about their further roles as an agent of change at their home institutions, only after the completion of the course they realized the significance of the training. This consequently had an impact on the final outcomes of the intended program.

Faculty development courses in 2018 differed from 2017 in that the scope of medical organizations was expanded. For instance, only medical schools took part in the courses in 2017, whereas in 2018 was also involved representatives of medical colleges. This decreased the pressure on medical schools to delegate a greater number of participants at one time. Nevertheless, the different aims of the medical organizations caused discrepancies in the 
content of the program. In contrast to European countries, in Kazakhstan the status of colleges differs from the status of schools. Colleges are similar to the level between post-secondary education and vocational education in European countries. The vision of the Ministry to enhance the qualifications of faculty members at colleges is to improve the quality of education. In addition, this will support consistency in medical education programs and students will easily be able to continue their studies after college. It is worth mentioning that informal conversations determined that faculty members from colleges felt challenged being on one team with faculty members from medical schools. They suggested that the MUK team should design a separate program for colleges. Although the college faculty members understand the Ministry's vision, in their mind they see the difference in statuses.

The participants in the 2018 program benefited from their interaction with an invited professor from the UK. This professor led courses for external faculty members and MUK trainers who needed to enhance their qualifications. The lectures were delivered in English. MUK avoided translating the program, instead having the professor adapt his/her lectures to the MUK program. Difficulties emerged with the language proficiencies of participants and the diminished level of natural communication between participants and the professor. After review lectures, faculty members were engaged in practical work and prepared their own program content with main objectives. They felt excited to present a piece of their own work even if it was in Russian or Kazakh. In contrast, MUK trainers could perfectly communicate in English with the professor and improved their conceptual understanding of deep learning and the principles of providing quality feedback, assessment, and program evaluation. MUK training staff remained satisfied with the training course. This kind of training is important for them because they are responsible for updating the content of the faculty development courses. They are therefore encouraged to bring fresh ideas and thoughts to current faculty development courses and keep track of new trends in education. It is very helpful for Kazakhstani faculty members to update their skills and competencies constantly in order to be competitive.

This study contributes to the existing knowledge in the following ways. First, it provides the experience of a Central Asian country in responding to changes in the higher education system triggered by globalization and thus contributes to the studies conducted by Phuong et al. (2015), Niehaus and Williams, (2016), Rigney, (2017), and ten Cate and Simonia, (2018), which explored faculty development experiences in Southeast Asian countries. Second, this study revealed that within the formation of groups of trainers, the delegated participants were not selected carefully enough, because course participants often felt unconfident and doubted whether they could share with their knowledge, contrary to the study conducted by Kim et al. (2017), which underlined the impediments of a hierarchical system that delegated senior members rather than younger, inexperienced members. It seems that the point that brings these two experiences together is that in neither of the cases did faculty members have a choice to express their interest or lack of interest in taking part in faculty development courses. In order to have motivated faculty members at training courses, it is important to have the proper selection procedure at the home institutions.

Regarding plagiarism issues emerged within assessment. What might have led faculty members to plagiarize was lack of time to respond to questions. Distance learning was aligned with faculty members' daily work at their home institutions. This meant that they had to do both their regular work and distance learning tasks simultaneously. It seems that the former Soviet era mentality still influences the faculty members' attitude. They still look for what they see as certain prescribed responses and seek them from books, articles, and internet resources, while at the same times neglecting their own personal experiences and opinions. Another reason could be faculty members' having too many work hours. Alongside their distance component tasks and written exams, they also have their classes to conduct, patients to meet, operations to do, and meetings to attend. In those daily routines, they are expected to find time and gain the highest scores. It is important to take into account these circumstances before making any judgments. Indeed, this is an obstacle at the moment for MUK trainers, but it could serve as an aim to eliminate this behavior in the future.

The MUK team very often receives criticism that the staff members of other universities were excluded from leading these modules. However, from discussions we revealed the challenge that universities have to cover the travel expenses of their trainers to MUK from their own budget rather than from the Ministry funding. In addition, the Ministry can support this project at the moment, but the future is unknown.

To conclude, the experience of MUK in faculty development revealed both advantages and disadvantages in the implementation of the pilot project (see Table 3).

Table 3. Advantages and Disadvantages of the Pilot Project

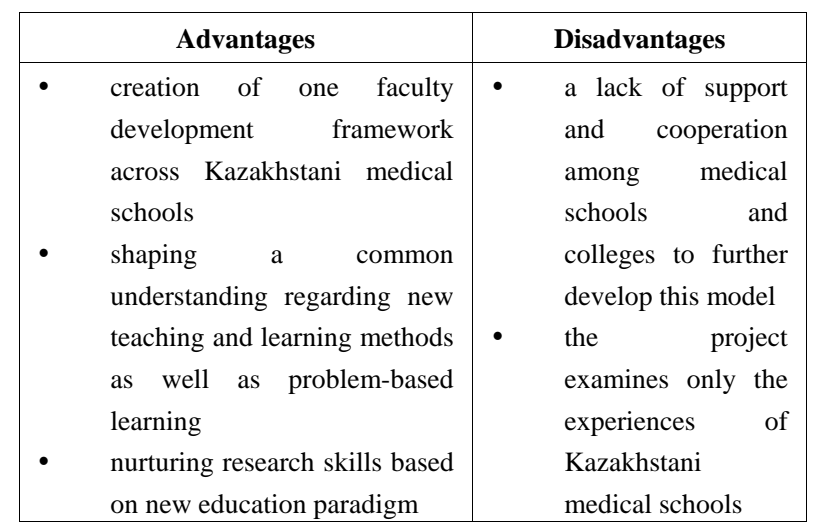




\section{Conclusions}

To conclude, a primary benefit of the project was to build one faculty development framework for medical schools. It was difficult to embed the priorities of medical educators in programs developed for educators in other fields and designed by the Ministry of Education and Science of the Republic of Kazakhstan. Therefore, this pilot project allowed medical schools leaders to determine a pivotal area of pedagogic competencies for medical faculty members.

A second benefit was transmitting of new teaching and learning approaches through discussion. This implies that faculty members experienced and practiced on themselves works in small groups, preparing presentation and presenting them, developing online courses, composing test questions. These effective teaching methods are imperative to engage students in the learning process, to move from teacher-centered learning, and to facilitate student-centered learning in order to help learners find their own path of professional growth. In addition, introduction of the problem-based learning course remains significant because medical cases are perfect approach to enhance students' critical thinking skills, working in team, problem solving skills and competencies.

Ultimately, research skills based on new education paradigm remain important because without research there are no future innovations or development of entrepreneurship and commercialization. Faculty members need to have a clear picture how knowledge construction is perceived and accepted at international level rather than in the country level. This enhance representativeness of Kazakhstani researchers and research among international scientific community. By this Kazakhstani people also can make contribution to knowledge and science development overall.

The main drawback of this pilot project is the lack of support and cooperation of medical schools and colleges to further develop this model. A limitation of this study is that the project examines only the experiences of Kazakhstani medical schools.

The results of the surveys have underlined that overall faculty members have been satisfied with the courses. Nevertheless, the low percentage of participants who achieved the status of trainer remains open to further discussion.

\section{REFERENCES}

[1] Akhmetova, G. (2017). Faculty Perceptions and Experiences of Curriculum Renewal in Kazakhstan's Higher Education (Unpublished Doctoral Dissertation). Nazarbayev University, Astana, Kazakhstan.

[2] Baran, E. (2016). Investigating faculty technology mentoring as a university-wide professional development model. Journal of Computing in Higher Education, 28, pp. 45-71.

[3] Brown, N., Bower, M., Skalicky,J., Wood, L., Donovan, D., Loch,B., Bloom, W., \& Joshi, N. (2010). A professional development framework for teaching in higher education. In M.Delvin, J.Nagy and A.Lichtenberg (Eds.) Research and Development in Higher Education: Reshaping Higher Education, 33 (pp.133-143). Melbourne, 6-9 July, 2010.

[4] Creswell, J. (2012). Educational Research: Planning, conducting, and evaluating quantitative and qualitative research $\left(4^{\text {th }} \mathrm{Ed}\right.$.). Pearson.

[5] Harden, R.M. (1992). Twelve tips to encourage better teaching. Medical Teacher (14)1, 1-6.

[6] Kim, D.H., Lee, J.H., Park, J., \& Shin, J.S. (2017). Process-oriented evaluation of an international faculty development program for Asian developing countries: a qualitative study. BMC Medical Education, 17 (206), pp.1-13.

[7] Merriam, Sh. B., \& Tisdell, E. J. (2016). Qualitative research: A guide to design and implementation. Jossey-Bass: A Wiley Brand. p.189.

[8] National Professional Development Framework for All Staff who teach in Higher Education (2016). Report. National Forum for the Enhancement of teaching and learning in higher education, Ireland.

[9] Niehaus, E., \& Williams, L. (2016). Faculty Transformation in Curriculum Transformation: The Role of Faculty Development in Campus Internationalization. Innovative Higher Education, 41, pp. 59-74.

[10] Perez-Sanagustin, M., Hilliger, I., Alario-Hoyos, C., Kloos, C.D., \& Rayyan, S. (2017). H-MOOC framework: reusing MOOCs for hybrid education. Journal of Computing in Higher Education, 29, pp.47-64.

[11] Phuong, T., Duong, H., \& McLean, G. (2015). Faculty Development in Southeast Asian Higher Education: a review of literature. Asia Pacific Education Review, 16, pp.107-117.

[12] Phuong, T., \& McLean, G. (2016). The experinces of Vietnamese university faculty in relation to their faculty development. Asia Pacific Education Review, 17, pp.599-608.

[13] Rigney, L. (2017). A Design and Evaluation Framework for Indigenisation of Australian Universities. In J. Frawley et al. (Eds.), Indigenous Pathways, Transitions and Participation in Higher Education. DOI 10.1007/978-981-10-4062-7_4

[14] Schutt, R.K. (2012). Investigating the social world: the process and practice of research $\left(7^{\text {th }} \mathrm{Ed}\right.$.). Pine Forge Press. $558 \mathrm{p}$.

[15] Teacher Development and Management Overview of Policy Briefs (2009). Continuous Professional Development: The Early Years. World Bank.

[16] Ten Cate, O., \& Simonia, G. (2018). Curriculum, Course, and Faculty Development for Case-Based Clinical Reasoning. In O.ten Cate \& et al. (Eds.), Principles and Practice of Case-based Clinical Reasoning Education, Innovation and Change in Professional Education 15, 
(pp.109-119). https://doi.org/10.1007/978-3-319--64828-6 -9

[17] The UK Professional Standards Framework for teaching and supporting learning in higher education (2011). Higher Education Academy, Guild HE, Universities UK.

[18] State Standard on Continuing Learning of the Republic of Kazakhstan. (2011). A Teacher of Medical Education and Science Organizations. The Ministry of Healthcare of the Republic of Kazakhstan. Astana.

[19] Zuev, A., \& Lentyaeva, T. (2015). Upravlenie kolichestvom stavok nauchno- pedagogicheskikh rabotnikov (NPR) i planom priema obuchayushikhsya obrazovatel'nykh organizatsii vysshego obrazovania [Management of quantity of teaching staff rates and enrollment plan of educational organization of higher education]. Vysshee Obrazovanie $v$ Rossii, 3, 24-32. Retrieved from http://vovr.ru/download.html 